\title{
Temporal changes in the genetic structure of the Daphnia species complex in Tjeukemeer, with evidence for backcrossing
}

\author{
PIET SPAAK* \\ Netherlands Institute of Ecology, Centre for Limnology, Rijksstraatweg 6, 3631 AC Nieuwers/uis, The Netherlands
}

\begin{abstract}
Temporal genetic variation was studied within the cyclic parthenogenetic Daphnia galeatacucullata species complex in Lake Tjeukemeer (The Netherlands). During three successive years, three allozyme loci were studied in order to compare the level of genetic variation in $D$. galeata $(\mathrm{G})$, D. cucullata $(\mathrm{C})$ and their interspecific hybrid $(\mathrm{C} \times \mathrm{G})$. This data set was used to investigate: whether $C \times G$ hybrids are regularly produced by the parental species and to what extent backcrossing takes place in this species complex. $\mathrm{G}$ and $\mathrm{C} \times \mathrm{G}$ were the most abundant taxa, whereas $C$ was only abundant in late summer and autumn. Genetic diversity was highest in $\mathrm{C}$, lowest in $\mathrm{G}$, and intermediate in $\mathrm{C} \times \mathrm{G}$. Pgm and Pgi allele frequencies of $\mathrm{C} \times \mathrm{G}$ were not intermediate to those of the parental species but were more similar to $G$ than to $C$. In addition, almost no significant deviations from Hardy-Weinberg were observed. An UPGMA analysis of Nei's genetic distances showed that $\mathrm{C} \times \mathrm{G}$ hybrids are more closely related to $\mathrm{G}$ (difference $<0.04$ ), than to $\mathrm{C}$ (difference 0.30 ). My data suggest, in accordance with other studies, that $\mathrm{C} \times \mathrm{G}$ hybrids are probably still formed by the parental species, though not necessarily every year. Furthermore, my data suggest that backcrossing occurred frequently, and led to introgression of $\mathrm{C}$ alleles into $\mathrm{G}$.
\end{abstract}

Keywords: allozymes, Cladocera, interspecific hybridization, introgression, parthenogenesis.

\section{Introduction}

Most theories on maintenance of hybrid zones are based on hybrid inferiority. For example the tension zone model (Barton \& Hewitt, 1985, 1989) predicts that hybrid zones are maintained by a dynamic equilibrium resulting from a balance between dispersal and either selection against hybrids, or frequencydependent selection against rare alleles. This model assumes that fitness values are independent of the environment. Therefore, tension zones can move and will tend to become established along natural barriers. It is clear that these types of hybrid zones can be maintained only through recurrent hybridization events, which are not necessary for hybrid populations of parthenogenetic taxa as here only one hybridization event is enough. Therefore, hybrids can be maintained by asexual reproduction.

Recent studies, using allozyme analysis, have shown that interspecific hybridization is a common

*Present address: Max-Planck-Institut für Limnologie, Postfach 165, D-24302 Plön, Germany. phenomenon within populations of cyclically parthenogenetic Daphnia (water flea) species (Hebert, 1985; Wolf \& Mort, 1986; Taylor \& Hebert, 1992); for review see Schwenk \& Spaak (1995). For example, in the Daphnia longispina group, many locations have been found where hybrids co-occur with one or both of their parental species (Gießler, 1987; Wolf, 1987; Müller \& Seitz, 1993), with some locations being dominated by hybrid taxa (Taylor \& Hebert, 1992; Spaak \& Hoekstra, 1993).

The evolutionary age of hybrids within the Daphnia longispina complex is still uncertain. Morphologically the hybrids make up a distinct group (Flößner \& Kraus, 1986), and also with respect to life histories, specific combinations of traits have been found for the hybrids, that distinguish them from their parental species (Weider \& Wolf, 1991; Weider, 1993; Spaak \& Hoekstra, 1995). The low numbers of backcrosses found in allozyme studies was the main reason why Flößner (1993) gave these hybrids a separate taxonomical status. However, recent molecular work on Daphnia hybrid 
species complexes suggests that interspecific Daphnia hybrids are not as genetically distinct as was assumed previously from allozyme studies. Differences in mitochondrial DNA sequences between hybrids and the maternal species are so small that relatively recent hybridization events should be assumed (Schwenk, 1993). Moreover, Schierwater et al (1994), using RAPD markers, showed that $D$. galeata $\times$ hyalina hybrid individuals possess a greater proportion of nuclear markers from $D$. hyalina than from $D$. galeata. Also, recent work on the North American Daphnia galeata mendotae-Daphnia rosea hybrid complex (Taylor \& Hebert, 1993) has revealed that in this hybrid complex backcrossing and introgression occur.

Most studies on interspecific hybridization in Daphnia have concentrated on the occurrence of genetic variation and on the geographical distribution of hybrids and parental species in both pond (Hebert et al., 1989a, 1993) and lake populations (Wolf, 1987; Gießler, 1987; Müller, 1993). These studies indicate that hybrid genotypes exist in almost all habitats where closely related Daphnia species co-occur (Hebert, 1985; Wolf \& Mort, 1986; Hebert et al., 1989b; Taylor \& Hebert, 1992; Weider \& Stich, 1992). However, only two of these studies (Wolf, 1987; Weider \& Stich, 1992) examined the temporal distribution of hybrid and parental taxa for a longer period (10 and 11 months, respectively). As far as I know, no studies on genetic variation within these taxa have been carried out which have included both the period of sexual reproduction in autumn and the following spring when these diapausing sexual eggs (ephippia) are supposed to hatch (Wolf \& Carvalho, 1989). Data on genetic heterogeneity over a long period are necessary to answer questions on how hybrid populations survive through the winter period. But above all, such temporal data can provide insight into seasonal adaptation of parentals and hybrids, in response to fluctuating selection pressures that act both on species and individual clones.

In this study, I report on the temporal distribution of genetic variation in D. galeata, D. cucullata and their interspecific hybrid in Lake Tjeukemeer between April 1989 and April 1992. Allozyme electrophoresis was used to distinguish between $D$. galeata, D. cucullata and the hybrid to determine seasonal fluctuations in this species complex. The aim was to investigate in which frequencies $D$. cucullata $\times$ galeata hybrid clones are yearly produced by the parental species. Furthermore, I wanted to study if and to what extend backcrossing takes places in this species complex. To test if hybrids are regularly produced genotype frequencies of the hybrid and the parental species were tested for deviations from Hardy-Weinberg (H.-W.) equilibrium. If hybrids are produced regularly by the parental species and there is no selection during this sexual phase, then no deviations from H.-W. equilibrium in the hybrid population are expected, at least not in spring when hybrids are supposed to hatch from ephippia. The same is predicted for both parental species, which produce males and ephippial females every year (Vijverberg \& Richter, 1982; pers. observ.). Assuming short-term, fluctuating selection and fitness differences between clones (Weider \& Wolf, 1991; Weider, 1993), one can expect seasonal differences in the clonal composition within the hybrid population.

In contrast, if hybrids were produced a long time ago and reproduced only parthenogenetically, as proposed by Flößner (1993), reduced genetic variation within hybrid populations would be expected because of long-term selection in favour of specific genotypes. One could compare this to the parental species, which provide new recombinant genotypes each year via sexual reproduction. In the latter case, either very low or nonexistent backcrossing rates would be expected between hybrids and parental species.

\section{Materials and methods}

\section{Laboratory methods}

Daphnia were sampled at five stations from Lake Tjeukemeer, situated in the north of the Netherlands, from 27 April 1989 to 28 April 1992. Samples were taken every two weeks during the growing season and monthly during the rest of the year using a $335 \mu \mathrm{m}$ tow net. The five samples were combined into a composite sample, and daphnids were picked from this sample and frozen in liquid nitrogen for subsequent electrophoretic analysis. Individual adult females were picked randomly and assayed using cellulose acetate electrophoresis following the methods of Hebert \& Beaton (1989). Generally 100 animals per sampling date were assayed for four enzyme loci: phosphoglucomutase (Pgm, EC 5.4.2.2), phosphoglucose isomerase ( $P g i$, EC 5.3.1.9), aldehyde oxidase (Ao, EC 1.2.3.1) and glutamaticoxaloacetatic transaminase (Got, EC 2.6.1.1). Initially also malate dehydrogenase $(\mathrm{Mdh}, \mathrm{EC}$ 1.1.1.37) was screened but gave no reproducible results for this species complex. Wolf \& Mort (1986) have shown that Got is a diagnostic marker for 
discrimination between $D$. galeata and $D$. cucullata. Daphnia galeata is fixed for the $F$ (fast) allele, whereas $D$. cucullata is fixed for the $S^{-}$(very slow) allele. Interspecific hybrids can be identified as heterozygotes $\left(S^{-} F\right)$ at Got. Variation at the Pgi and $P g m$ loci made it possible to identify a number of two-locus genotypes within each taxon. Ao was monomorphic.

\section{Genetic structure}

Wright's $(1965)$ fixation index $\left(F_{\text {IT }}\right)$ was calculated for both polymorphic loci, Pgi and Pgm, as the deviation of the observed proportion of heterozygous individuals from the proportion expected under H.-W. equilibrium: $F_{\mathrm{IT}}=1-H_{\mathrm{o}} / H_{\mathrm{e}}$. Positive values of the index imply a deficiency of heterozygotes at that locus, whereas negative values indicate an excess of heterozygotes. Although hybrids are defined a priori as heterozygous $S^{-} F$ for Got and, therefore, do not constitute a randomly mating group, H.-W. analyses were performed to test the hypothesis that 'hybrids are formed each year by random mating among the parental species and hatch from ephippia in the spring'. Significant deviations from H.-W. expectations were tested using the BIOSYS-1 computer program (Swofford \& Selander, 1989) with subroutine HDYwBG using Levene's correction for small sample sizes. Because the chisquared test is suspect in cases where expected genotype frequencies are low, the analysis was carried out with three pooled genotype classes. The resulting chi-squared value was used with one degree of freedom. Because of the fairly large numbers of simultaneous tests, a sequential Bonferroni test procedure (Rice, 1989) was performed. The initial critical probability value was set at $P<0.05 / N$, where $N$ represents the number of nonindependent tests.

Clonal diversity was calculated for all taxa on a monthly basis, by pooling the sampling dates within a month; pooled monthly samples with fewer than 20 individuals of a taxon were excluded from the analysis. As a measure of clonal diversity, I used Simpson's (1949) index of concentration, $C=\Sigma p_{i}^{2}$, where $p_{i}$ is the frequency of the $i$ th clone in the sample, and the summation is over all clones. Clonal diversity $D$ was calculated as $D=-\log C$ (Pielou, 1975). This diversity is a composite of abundance and evenness: it exhibits low values when a single clone is overwhelmingly predominant, and higher values when clonal numbers are larger and evenly distributed.

\section{Genetic distances}

Unbiased genetic distances (Nei, 1978) among the samples of the different taxa were calculated and the relatedness of the different samples was assessed using the unweighed pair-group (UPGMA) clustering program of BIOSYs-1 (Swofford \& Selander, 1989). Because the number of samples was large, analysis of genetic distances was based on mean frequency data per taxon per month, restricted to Pgi and Pgm and using the Got genotypes to define the taxa. Samples of fewer than 20 individuals per taxon were excluded from the analysis. The samples of the different months served as replicates.

\section{Results}

\section{Allele and genotype frequencies}

Based on the Got electromorphs, specimens could be assigned to D. galeata $(F F), D$. cucullata $\left(S^{-} S^{-}\right)$ or the interspecific hybrid $D$. cucullata $\times$ galeata $\left(S^{-} F\right)$. Eighteen samples per year were analysed from 1989, 1990 and 1991, and two from 1992. The relative densities of the three species are plotted as Got genotypes (Fig. 1) (the complete data set of this study is published in Spaak (1994) and is available on request from the author). There were large differences between the three years. At the beginning of $1989, D$. galeata dominated the Daphnia community, then the hybrid took over in July and $D$. cucullata had a peak during August-September. In 1990, D. galeata dominated during the first half of the year but from July to October the hybrid was dominant. Daphnia cucullata had only a relatively low peak abundance in September. In contrast to the two preceding years, $D$. galeata dominated for almost a year from Octoher 1990 to August 1991, although densities were low during the winter period (P. Spaak \& J. R. Hoekstra, unpublished observations). In October 1991, the annual maximum of $D$. cucullata was observed again, after which the hybrid dominated the Daphnia assemblage.

A total of three alleles was detected at the Pgm locus for the three taxa. In the $D$. galeata population, the $F$ allele was most common ( 63 per cent, Table 1). Pgm allele frequencies of the hybrid are comparable with those of $D$. galeata, although the $S$ allele was detected at a slightly higher mean frequency (11 per cent). The pattern in $D$. cucullata differed: $M$ was the most common allele (50 per cent) and the mean frequencies of the $F$ and $S$ alleles were similar (26 and 23 per cent, respectively). H.-W. analyses revealed no significant deviations from random mating within $D$. galeata. The 


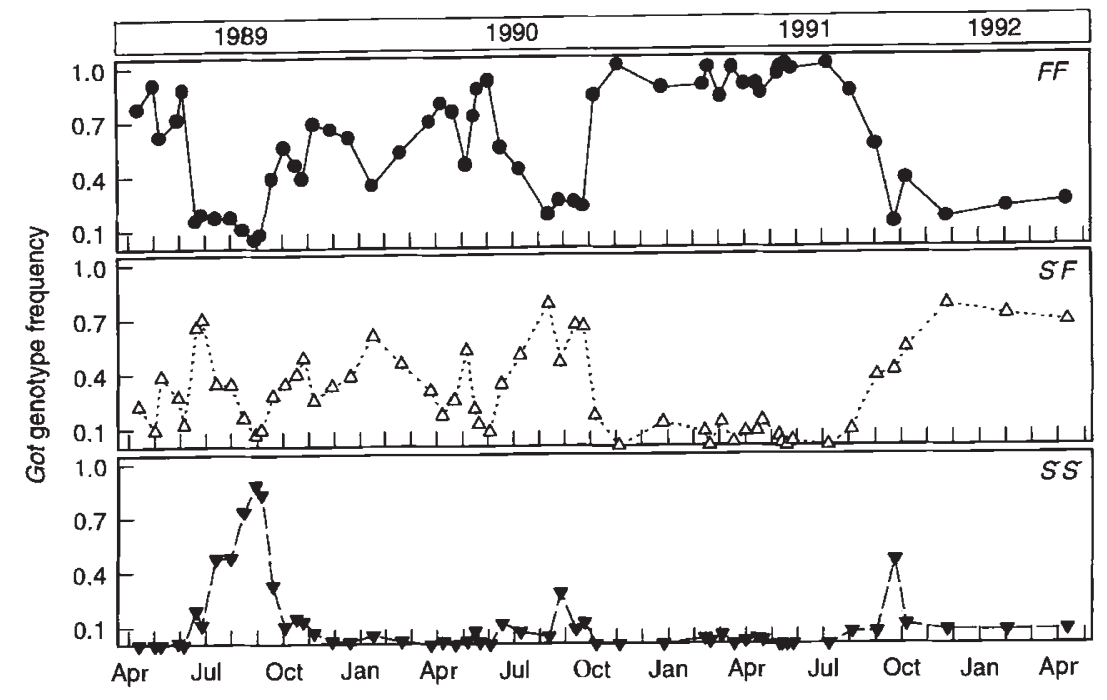

Fig. 1 Relative abundances of the three $G o t$ genotypes $(F F=$ Daphnia galeata, $S^{-} S^{-}=D$. cucullata and $S^{-} F=D$. cuc. $\times$ gal. ) in the Tjeukemeer during the period April 1989-April 1992.

Table 1 Mean allele frequencies (All. freq.) at Pgm and Pgi for all sampling dates of Daphnia cucullata, D. galeata and their interspecific hybrid

\begin{tabular}{|c|c|c|c|c|c|}
\hline & & D. cucullata & D. cuc. $\times$ gal. & D. galeata & $\begin{array}{c}\text { D. galeata } \\
\text { (Germany)* }\end{array}$ \\
\hline Locus & Allele & All. freq. & All. freq. & All. freq. & All. freq. \\
\hline \multirow[t]{5}{*}{$P g m$} & $S^{-}$ & - & - & - & 0.020 \\
\hline & $S$ & 0.234 & 0.108 & 0.079 & 0.182 \\
\hline & $M$ & 0.504 & 0.301 & 0.295 & 0.746 \\
\hline & $F$ & 0.263 & 0.591 & 0.625 & 0.052 \\
\hline & Sample size & 550 & 1720 & 3402 & 277 \\
\hline \multirow[t]{5}{*}{$P g i$} & $S^{-}$ & 0.042 & 0.004 & - & - \\
\hline & $S$ & 0.517 & 0.186 & 0.035 & - \\
\hline & $M$ & 0.415 & 0.786 & 0.951 & 0.915 \\
\hline & $F$ & 0.026 & 0.024 & 0.014 & 0.085 \\
\hline & Sample size & 557 & 1760 & 3456 & 282 \\
\hline
\end{tabular}

The last column gives pooled data of two German lakes (Hegbachsee and Meerfelder Maar) where D. cucullata does not occur (J. Müller, pers. comm.). Frequency of proposed introgressed allele is in bold.

*Hegbachsee was sampled Jul., Nov. 1989, and Apr. 1990. Meerfelder Maar was supplied in May, Jun., Nov. 1989 and May 1990.

positive values of $F_{\mathrm{IT}}$ on 31 of the 51 dates (Fig. 2), and a mean value of 0.023 , indicate almost no heterozygote deficiencies at the Pgm locus. For $D$. cucullata, 10 of the $15 F_{\text {IT }}$ values were negative, and two of these were significantly different from H.-W. expectation (28 July 1989 and 12 September 1989). The mean $F_{\text {IT }}$ ( -0.128 over 15 dates) also indicates an excess of heterozygotes at the Pgm locus for $D$. cucullata. The hybrid showed a significant deviation from H.-W. on one out of 38 occasions (21 Novem- ber 1989). Negative values of $F_{\text {IT }}$ were found on 20 dates, with a mean $F_{\text {IT }}$ of -0.033 .

At the Pgi locus, a total of four alleles was found of which the $S^{-}$allele was not found in D. galeata. Daphnia galeata was almost fixed for the $M$ allele (Table 1) whereas $D$. cucullata showed comparable frequencies for the $M$ and $S$ alleles (grand means of 42 per cent and 52 per cent, respectively). The hybrid differed from $D$. galeata in the frequency of the $S$ allele with mean frequencies of 19 per cent 
Fig. $2 F_{\text {IT }}$ values during the study period for Pgm and Pgi plotted for all three taxa of Daphnia. Data points were smoothed by a three-point running mean.
Fig. 3 Clonal diversity $D$, plotted per month, calculated as the negative logarithm of Simpson's index of concentration (see text) for the three taxa of Daphnia.
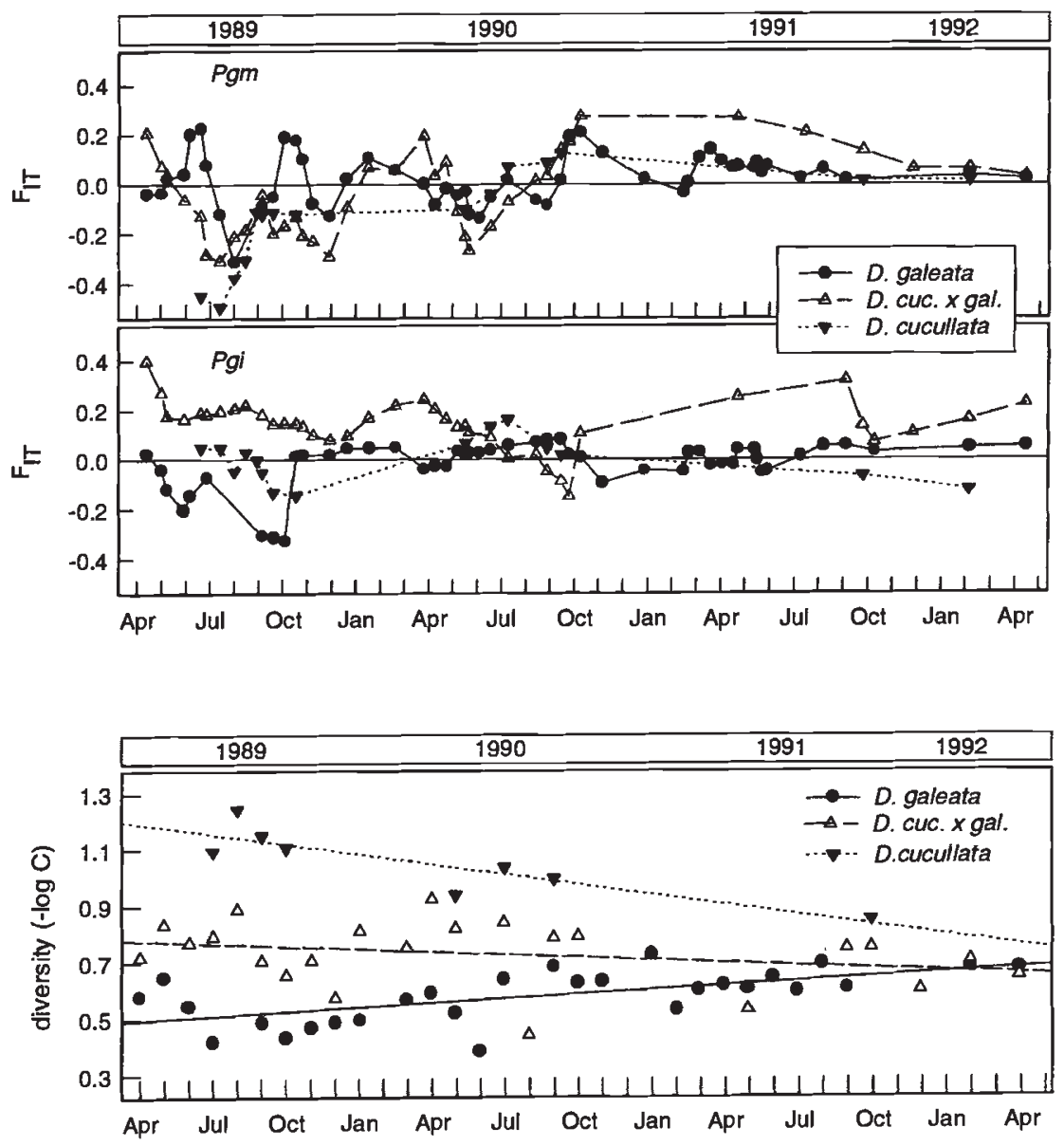

and 4 per cent, respectively (Table 1). Significant deviations from H.-W. expectations were found for both $D$. galeata and the hybrid in three cases. For $D$. galeata, these deviations were all heterozygote excesses (negative $F_{\text {IT }}$ ), whereas for the hybrid, two dates showed a positive $F_{\text {IT }}$ and one a negative value (Fig. 2). For D. cucullata, no significant deviations from H.-W. were found. Overall mean $F_{\mathrm{IT}}$ values were $-0.0018,0.142$ and -0.005 for $D$. galeata, the hybrid and $D$. cucullata, respectively.

\section{Genetic diversity}

Several multilocus (Got-Pgi-Pgm) genotypes were found for all taxa on all sampling dates. The minima were seven on 3 April 1991 and 24 July 1991, whereas the maximum was 41 multilocus genotypes on 24 July 1990 . The number of detected clones was the highest for $D$. cucullata and the lowest for $D$. galeata. This is reflected in the clonal diversity $(D)$ values shown in Fig. 3. Regression lines for the change of clonal diversity with time were signifi- cantly nonparallel $\left(F_{2,53}=11.69, P<0.001\right)$. When present in the lake $D$. cucullata always had the highest value, although for this taxon, a trend of decreasing clonal diversity was observed with $r^{2}=0.73$ for the regression slope. Daphnia galeata had a lower $D$ compared with the hybrid, but $D$ increased significantly during the study period $\left(r^{2}=0.32\right)$. The regression coefficient of the clonal diversity values of the hybrid with time was not significant different from zero $\left(r^{2}=0.06\right)$. Two genotypes dominated the $D$. galeata population throughout the study period: (Pgi-Pgm) $M M M F$ and $M M F F$; only in one month was another genotype found in higher frequencies: MMSF in January 1991 (Fig. 4a).

Figure 4 presents only those genotypes that had a frequency of 10 per cent or higher in at least one month of the study period. The number of different Pgi-Pgm genotypes found for D. cucullata was so high that only six genotypes fulfilled this criterion (Fig. 4c). These genotypes represented between 50 and 60 per cent of the total population. The rest of the population consisted of a large number of 'rare' 


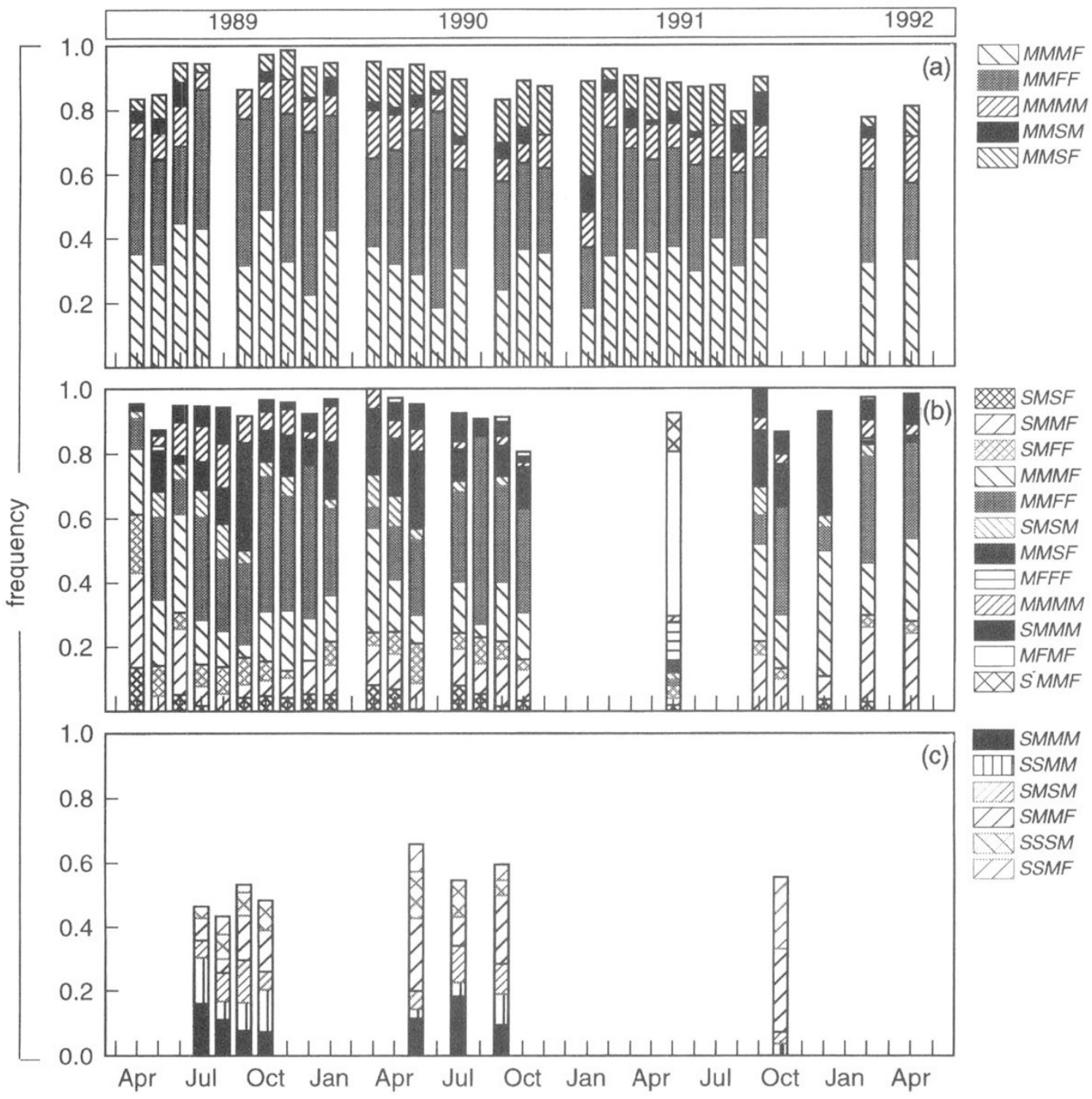

Fig. 4 Relative densities of Pgi-Pgm genotypes for the three taxa, Daphnia galeata (a), D. cuc. $\times$ gal. (b) and D. cucullata (c) pooled per month. Only those genotypes are plotted which had, at least in one month, a relative density of 10 per cent or more. Months with fewer than 20 individuals per taxon were not plotted.

genotypes. The pattern for the hybrid was intermediate to the parental species (Fig. 4b). Some genotypes dominated on most dates, for example $M M M F$ and $M M F F$. But in contrast to the stable pattern observed in $D$. galeata, the dominant genotypes of the hybrid were almost completely replaced by others on some occasions. For example, in May 1991 the genotype composition was completely different from October 1990. In spring 1991, when the Daphnia population was dominated by $D$. galeata (Fig. 1), MFMF was the dominant hybrid genotype.
Although the pattern is striking, the overall densities of the hybrid were low during that period (i.e. only the May sample had more than 20 individuals).

\section{Genetic distances}

The UPGMA cluster analysis of Nei's genetic distances grouped the monthly pooled samples into two separate groups, which represented the parental species (Fig. 5). Although the hybrid did not form one separate group they clustered closer to $D$.

(D) The Genetical Society of Great Britain, Heredity, 76, 539-548. 


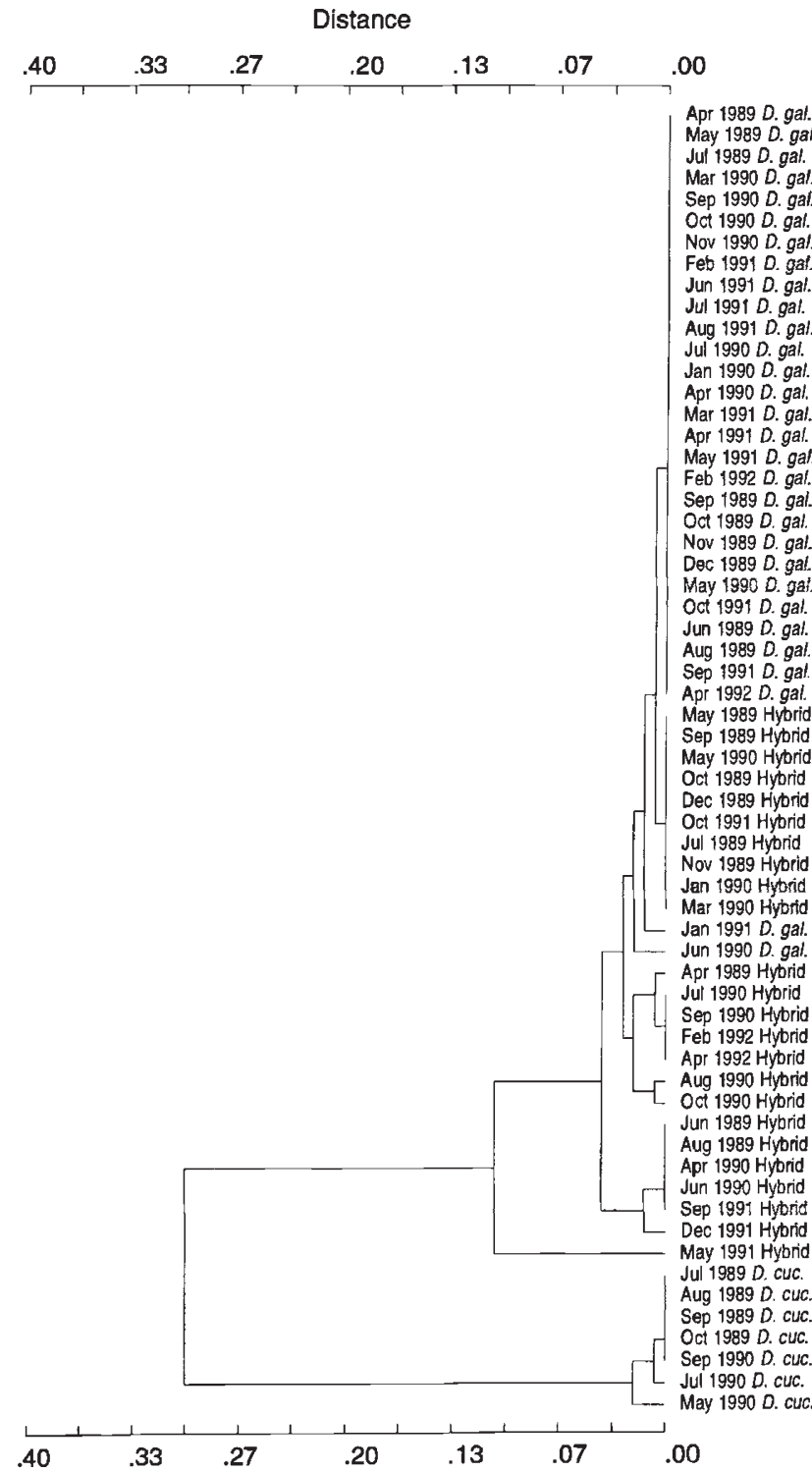

Fig. 5 UPGMA clustering of Nei's genetic distances, among monthly pooled samples of Daphnia taxa, calculated for Pgi and Pgm.

galeata than to $D$. cucullata. Two exceptions were observed: D. galeata samples of June 1990 and January 1991 clustered among the hybrids. The differences between $D$. galeata and the hybrid were, with one exception (May 1991), smaller than 0.04, whereas $D$. galeata was separated from $D$. cucullata by a mean genetic distance of 0.30 , thus indicating a closer relationship between the hybrid and $D$. galeata than between it and $D$. cucullata.

\section{Discussion}

\section{Genetic variation}

The three Daphnia taxa in Lake Tjeukemeer showed high genetic variability. A total of 100 three-locus (Got-Pgi-Pgm) genotypes was found, 26 in $D$. galeata, 42 in D. cucullata and 32 in the hybrid. Such a high level of genetic variation has also been reported for other populations of the $D$. longispina group (Mort \& Wolf, 1985; Weider \& Stich, 1992; Müller \& Seitz 1993). In the Tjeukemeer, D. cucullata had the highest diversity during all three years. The hybrids were intermediate to the parental species in their clonal diversity. The three groups differed in their diversity levels especially during 1989 and the first part of 1990 (Fig. 3). During the last year of the study period, clonal diversity values were converging and showed no differences any more in 1992. In contrast, Weider \& Stich (1992), who studied $D$. galeata, D. hyalina and their interspecific hybrid in the Bodensee, found the lowest number of genotypes for the hybrid (they reported 17 , six and five different genotypes, respectively, in an 11-month study). This might indicate that hybridization events in the Bodensee have been rare compared to the Tjeukemeer, because with a low hybridization rate, fewer new genotypes will be formed, whereas the chance of extinction of genotypes remains the same. Indeed, no ephippial females or males were found in their study, although earlier studies on the Daphnia population in the Bodensee reported low frequencies of males and ephippial females (Einsle, 1983; Stich, 1989).

Daphnia cucullata seems to be a typical summerautumn species (Vijverberg \& Richter, 1982; Wolf, 1987) (Fig. 1). Because D. cucullata is not found in the open water of the Tjeukemeer during most winters, this species probably overwinters as sexually produced ephippia on the bottom of the lake. If the main part of the population is established each year from ephippial hatchlings, one would expect high genetic variation. This would explain the high genetic diversity of $D$. cucullata compared with the two other taxa in the lake, which were found in higher densities during the winter period also (P. Spaak \& J. R. Hoekstra, unpublished observations).

Genotype frequencies for both parental species and the hybrid were almost continuously in HardyWeinberg equilibrium (with a few exceptions). According to Hebert (1987), this could be caused by regular massive emergences of young from sexually produced ephippial eggs. Only indirect information is available on sexual egg production. Sexual females 
and males were found during all three years: sexual $D$. galeata females were found in May-June, whereas sexual $D$. cucullata females were observed in October-November. In 1989, ephippial hybrids were found in spring, but in 1990 and 1991, they were found in autumn (Spaak, 1995). It seems that in most years temporal mating barriers exist between $D$. galeata and D. cucullata. Only in spring 1989 were the sexual forms of both species observed together. These observations show that hybridization events are still possible, but they probably occur at very low frequencies. They also show that the possibility of producing backcrosses is much larger compared to the production of $F_{1}$ hybrids. An infrequent production of $F_{1}$ hybrids is also supported by data from Wolf \& Carvalho (1989), who studied the hatching of ephippia from the D. longispina species group in situ. They found hatchlings of both parental species (D. galeata and $D$. hyalina) present in the lake, but only one out of 56 individuals had a hybrid genotype.

\section{Evidence for introgression}

My observations are in agreement with the notion that introgression (defined as gene exchange among taxa by mating) between $D$. galeata and $D$. cucullata occurs. The UPGMA dendrogram of genetic distances (Fig. 5) shows clear separation between D. galeata, the hybrid and $D$. cucullata, even without using Got in the analysis. In addition, $D$. galeata and hybrid samples were more closely related to each other than to $D$. cucullata. In all but one case, the genetic distance between $D$. galeata and the hybrid was $<0.04$. If one includes Got in the analysis then this distance estimate is 0.13 between the hybrid and $D$. galeata, and 0.71 between these two taxa and $D$. cucullata. However, Nei's genetic distance between conspecific taxa are ordinarily less than 0.10 and rarely exceed 0.20 (Ayala, 1983). These data suggest that $D$. galeata and the hybrid may constitute an interbreeding group.

Also allele frequencies of the hybrid are very similar to $D$. galeata (Table 1 ) but differ greatly from $D$. cucullata. If the hybrid was formed on a regular basis, and consisted only of asexual descendants of $F_{1}$ individuals, a more intermediate pattern would be expected. My observation of a probably high backcrossing rate in the Tjeukemeer is in accordance with other recent studies. Taylor \& Hebert (1993) showed that nuclear gene flow occurs between two American members of the $D$. longispina group ( $D$. galeata mendotae and $D$. rosea), though mtDNA introgression was not observed. Recently, Streit et al.
(1994) found an unbalanced distribution of diagnostic parent RAPD markers in $D$. galeata $\times$ hyalina hybrid clones, which provides further evidence for backcrossing in this species complex.

Why the hybrids are crossing back to $D$. galeata and not to D. cucullata is difficult to understand from the ecological data available. Sexual hybrid females and males co-occur both with sexual $D$. galeata and D. cucullata (Spaak, 1995) which would make backcrossing with both parental species possible. And although life histories of the hybrid have more in common with D. galeata (Spaak \& Hoekstra, 1995) a larger niche overlap between the hybrid and $D$. cucullata was observed by Boersma (1995). Possible reasons for the strong backcrossing towards $D$. galeata could be postmating barriers between the hybrid and $D$. cucullata. Another possibility could be differences in viability of resting eggs so that backcrosses with $D$. cucullata do not hatch as well as backcrosses with $D$. galeata. In the $D$. longispina group earlier evidence was found for unidirectional hybridization (Schwenk, 1993), whereas a mtDNA study showed that for $D$. galeata $\times$ cucullata hybrids in the Tjeukemeer, D. cucullata is the maternal species in most cases (Schwenk, pers. comm.). The processes which lead to these unbalanced mating patterns need further study.

In this study only one species-specific marker was available. Therefore individual $F_{1}$ hybrids could not be distinguished from backcrosses within the hybrid group. Comparison of allele frequencies of different samples shows that $F_{1}$ hybrids are probably rare. However this observation says nothing about the individual animals in these samples. A low percentage of real $F_{1}$ hybrids in a sample is not expected to change overall allele or genotype frequencies and would therefore remain undetected.

In conclusion, the hypothesis of contemporary sexual production of hybrids could not be rejected. Allele frequencies of the hybrid and a close clustering of the hybrid to $D$. galeata suggest that if these hybridization events occur they must be rare. Furthermore, it seems from the phenology of both parental species (Spaak, 1995) that both parental species are reproductively isolated during most years. The high level of genetic variability within the hybrid population can be explained by either sexual recombination among hybrids or gene exchange with the parental species, or both. The strong genetic similarity between the hybrid and the $D$. galeata populations can have important consequences for the life histories of these hybrid taxa. Because Spaak \& Hoekstra (1995) showed that these hybrids have fitness values more comparable to $D$. galeata, it is 
clear that the genetic composition and life histories of hybrid Daphnia swarms need further study. However more species-specific markers are needed to classify individual hybrids as $F_{1}$ s or backcrosses.

\section{Acknowledgements}

I thank Koos Swart and Steven Visser for collecting the samples and Rob Hoekstra for doing most of the electrophoresis. I am especially grateful to Jakob Müller who provided me with unpublished data about the German lakes. Luc de Meester, Maarten Boersma, Jos van Damme, Ramesh Gulati, Rob Hoekstra, Joop Ringelberg, Klaus Schwenk, Onno van Tongeren, Koos Vijverberg, Larry Weider and two anonymous reviewers are acknowledged for stimulating discussions and comments on earlier versions of the manuscript.

\section{References}

AYALA, F. J. 1983. Enzymes as taxonomic characters. In: Oxford, G. S. and Rollinson, D. (eds) Protein Polymorphism: Adaptive and Taxonomic Significance, pp. 3-26. Academic Press, London.

BARTON, N. H. AND HEwITT, H. H. 1985. Analysis of hybrid zones. Ann. Rev. Ecol. Syst., 16, 113-148.

BARTON, N. H. AND HEWITT, H. H. 1989. Adaption, speciation and hybrid zones. Nature, 341, 497-503.

BOERSMA, M. 1995. Competition in natural populations of Daphnia. Oecologia, 103, 309-318.

EINSLE, U. 1983. Die Entwicklung und Männchenbildung der Daphnia Population im Bodensee-Obersee 1956-1980. Schweiz. Z. Hydrol., 45, 321-332.

FLÖßNER, D. 1993. Zur Kenntnis einiger DaphniaHybriden. Limnologica, 23, 71-79.

FLÖBNER, D. AND KRAUS, K. 1986. On the taxonomy of the Daphnia hyalina-galeata complex (Crustacea: Cladocera). Hydrobiologia, 137, 97-115.

GIEBLER, s. 1987. Mikroevolution und Populationsgenetik im Daphnia galeata/hyalina/cucullata-Komplex (Crustacea: Cladocera) eine Freilandsanalyse. Ph.D. Thesis, University of Munich, Germany.

HEBERT, P. D. N. 1985. Interspecific hybridization between cyclic parthenogens. Evolution, 39, 216-220.

HEBERT, P. D. N. 1987. Genetics of Daphnia. In: Peters, R. H. and de Bernardi, R. (eds) Daphnia. Memorie Istitute Italiano Di Idrobiologia, 45, 439-460.

HEBERT, P. D. N. AND BEATON, M. J. 1989. Methodologies for Allozyme Analysis using Cellulose Acetate Electrophoresis. Helena Laboratories, Beaumont, TX.

HEBERT, P. D. N., BEATON, M. J., SCHWARTZ, S. S. AND STANTON, D. J. 1989a. Polyphyletic origins of asexuality in Daphnia pulex. I. Breeding-system variation and levels of clonal diversity. Evolution, 43, 1004-1015.

HEBERT, P. D. N., SCHWARTZ, s. S. AND HRBÁČEK, J. 1989 b. Patterns of genotypic diversity in Czechoslovakian
Daphnia. Heredity, 62, 207-216.

HEBERT, P. D. N., SCHWARTZ, S. S., WARD, R. D. AND FINSTON, T. L. 1993. Macrogeographic patterns of breeding system diversity in the Daphnia pulex group. I. Breeding systems of Canadian populations. Heredity, 70, $148-161$.

MORT, M. A. AND WOLF, H. G. 1985. Enzyme variability in large-lake Daphnia populations. Heredity, 55, 27-36.

MÜLlER, J. 1993. Räumliche und zeitliche Variabilität der genetischen Struktur natürlicher Cladoceren Populationen (Crustacea: Cladocera). Ph.D. Thesis, Johannes Gutenberg Universität, Mainz, Germany.

MÜlleR, J. AND SEITZ, A. 1993. Habitat partitioning and differential vertical migration of some Daphnia genotypes in a lake. Arch. Hydrobiol. Beih. Ergebn. Limnol., 39, 167-174.

NEl, M. 1978. Estimation of average heterozygosity and genetic distance from a small number of individuals. Genetics, 89, 583-590.

PIELOU, E. C. 1975. Ecological Diversity. Wiley-Interscience Publication, New York.

RICE, W. R. 1989. Analyzing tables of statistical tests. Evolution, 43, 223-225.

SCHIERWATER, B., ENDER, A., SCHWENK, K., SPAAK, P. AND STREIT, B. 1994. The evolutionary ecology of Daphnia. In: Schierwater, B., Streit, B., Wagner, G. and DeSalle, R. (eds) Molecular Approaches to Ecology and Evolution, pp. 495-508. Birkhäuser Verlag, Basel.

sCHWENK, к. 1993. Interspecific hybridization in Daphnia: distinction and origin of hybrid matrilines. Mol. Biol. Evol., 10, 1289-1302.

SCHWENK, K. AND SPAAK, P. 1995. Evolutionary and ecological consequences of interspecific hybridization in cladocerans. Experientia, 51, 465-481.

SIMPSON, E. H. 1949. Measurement of diversity. Nature, $163,688$.

SPAAK, P. 1994. Genetical Ecology of a Coexisting Daphnia Hybrid Species Complex. Ph.D. Thesis, University of Utrecht, The Netherlands.

SPAAK, P. 1995. Sexual reproduction in Daphnia: interspecific differences in a hybrid species complex. Oecologia, 104, 501-507.

SPAAK, P. AND HOEKSTRA, J. R. 1993. Clonal structure of the Daphnia population in Lake Maarsseveen: its implications for diel vertical migration. Arch. Hydrobiol. Beih. Ergebn. Limnol., 39, 157-165.

SPAAK, P. AND HOEKSTRA, J. R. 1995. Life history variation and the coexistence of a Daphnia hybrid with its parental species. Ecology, 76, 553-564.

STiCH, H. B. 1989. Seasonal changes of diel vertical migration of crustacean plankton in Lake Constance. Arch. Hydrobiol. (Monographische Beiträge), 3, 355-405.

STREIT, B., STÄDLER, T., SCHWENK, K., ENDER, A., KUHN, K. AND SCHIERWATER, B. 1994. Natural hybridization in freshwater animals: Ecological implications and molecular approaches. Naturwissenschaften, 81, 65-73.

SWOFFORD, D. L. AND SELANDER, R. B. 1989. BIOSYS-1. $A$ computer program for the analysis of allelic variation in population genetics and biochemical systematics. Release 
1.7. University of Illinois, Urbana, Illinois

TAYLOR, D. J. AND HEBERT, P. D. N. 1992. Daphnia galeata mendotae as a cryptic species complex with interspecific hybrids. Limnol. Oceanogr, 37, 658-665.

TAYLOR, D. J. AND HEBERT, P. D. N. 1993. Habitat-dependent hybrid parentage and differential introgression between neighboringly sympatric Daphnia species. Proc. Natl. Acad. Sci. U.S.A., 90, 7079-7083.

VIJVERBERG, J. AND RICHTER, A. F. 1982. Population dynamics and production of Daphnia hyalina Leydig and Daphnia cucullata Sars in Tjeukemeer. Hydrobiologia, 95, 235-259.

WEIDER, L. J. 1993. Niche breadth and life history variation in a hybrid Daphnia complex. Ecology, 74, 935-943.

WEIDER, L. J. AND STICH, H. B. 1992. Spatial and temporal heterogeneity of Daphnia in Lake Constance-intraspecific and interspecific comparisons. Limnol. Oceanogr. $37,1327-1334$.
WEIDER, L. J. AND WOLF, H. G. 1991. Life-history variation in a hybrid species complex of Daphnia. Oecologia, 87, 506-513.

WOLF, H. G. 1987. Interspecific hybridization between Daphnia hyalina, D. galeata and D. cucullata and seasonal abundance of these species and their hybrids. Hydrobiologia, 145, 213-217.

WOLF, H. G. AND CARVAlHo, G. R. 1989. Resting eggs of lake-Daphnia. II. In situ observations on the hatching of eggs and their contribution to population and community structure. Freshwat. Biol., 22, 471-478.

WOLF, H. G. AND MORT, M. A. 1986. Interspecific hybridization underlies phenotypic variability in Daphnia populations. Oecologia, 68, 507-511.

WRIGHT, s. 1965. The interpretation of population structure by F-statistics with special regard to systems of mating. Evolution, 19, 395-420. 